\title{
Distinct mesodermal signals, including BMPs from the septum transversum mesenchyme, are required in combination for hepatogenesis from the endoderm
}

\author{
Jennifer M. Rossi, ${ }^{1,2}$ N. Ray Dunn, ${ }^{3}$ Brigid L.M. Hogan, ${ }^{3}$ and Kenneth S. Zaret ${ }^{2,4}$ \\ ${ }^{1}$ Department of Molecular Biology, Cell Biology, and Biochemistry, Brown University, Providence, Rhode Island 02912, \\ USA; ${ }^{2}$ Cell and Developmental Biology Program, Fox Chase Cancer Center, Philadelphia, Pennsylvania 19111, USA; \\ ${ }^{3}$ Department of Cell Biology, Vanderbilt University Medical Center, Nashville, Tennessee 37232, USA
}

\begin{abstract}
Mesodermal signaling is critical for patterning the embryonic endoderm into different tissue domains. Classical tissue transplant experiments in the chick and recent studies in the mouse indicated that interactions with the cardiogenic mesoderm are necessary and sufficient to induce the liver in the ventral foregut endoderm. Using molecular markers and functional assays, we now show that septum transversum mesenchyme cells, a distinct mesoderm cell type, are closely apposed to the ventral endoderm and contribute to hepatic induction. Specifically, using a mouse Bmp4 null mutation and an inhibitor of BMPs, we find that BMP signaling from the septum transversum mesenchyme is necessary to induce liver genes in the endoderm and to exclude a pancreatic fate. BMPs apparently function, in part, by affecting the levels of the GATA4 transcription factor, and work in parallel to FGF signaling from the cardiac mesoderm. BMP signaling also appears critical for morphogenetic growth of the hepatic endoderm into a liver bud. Thus, the endodermal domain for the liver is specified by simultaneous signaling from distinct mesodermal sources.
\end{abstract}

[Key Words: BMP; liver; mesoderm; endoderm; septum transversum]

Received April 17, 2001; revised version accepted June 1, 2001.

The vertebrate liver develops from the ventral foregut endoderm, a multipotent tissue that also gives rise to the lung, pancreas, and thyroid (Wells and Melton 1999; Zaret 2000). Studies of model organisms such as Drosophila have shown that different regions of the gut are patterned by signals from the overlying mesoderm. For example, Dpp, a member of the TGF $\beta / B M P$ superfamily of signaling molecules, is secreted from the embryonic fly mesoderm to promote the differentiation of the gut endoderm (Immerglück et al. 1990; Panganiban et al. 1990). Dpp synergizes with ligands that activate growth factor receptors in the fly midgut (Szuts et al. 1998). In this study, we investigated how different mesodermal signaling molecules converge to pattern tissue development within the mammalian gut.

Transplantation studies with chick and mouse embryos have demonstrated that successive inductive interactions occur between the mesoderm and the endoderm to promote hepatic development (LeDouarin 1975; Houssaint 1980; Fukuda-Taira 1981; Gualdi et al. 1996).

\footnotetext{
${ }^{4}$ Corresponding author.

E-MAIL zaret@fccc.edu; FAX (215) 379-4305.

Article and publication are at http://www.genesdev.org/cgi/doi/10.1101/ gad.904601.
}

The first inductive signal, by the $7-8$ somite stage, was shown to originate from the cardiac mesoderm and cause the activation of liver-specific genes and the proliferation of the nascent hepatic endoderm (LeDouarin 1975; Gualdi et al. 1996). Recently, fibroblast growth factors (FGFs), which are secreted by the cardiac mesoderm, were shown to be necessary and sufficient for cardiac induction of liver gene expression and endoderm proliferation in an explant assay (Jung et al. 1999b). Classical tissue explant studies also revealed a second step of hepatic induction from the septum transversum mesenchyme, a tissue originating from the lateral plate mesoderm (LeDouarin 1975; Sherer 1975; Fukuda-Taira 1981). Septum transversum mesenchyme cells contribute to the epicardium and diaphragm and promote outgrowth of the liver bud into the septum transversum. The septum transversum mesenchyme cells are tightly associated with the cardiac mesoderm and, therefore, could contribute to the initial stage of hepatic induction as well. In this study, we investigated the hypothesis that the septum transversum mesenchyme cells work in conjunction with cardiac mesoderm to promote the initial phase of hepatic induction. The work serves as a model to define how multiple mesodermal signals converge to pattern the endoderm into different tissues. 
Many developmentally important proteins are expressed in the mesoderm surrounding the foregut endoderm at the time of liver specification. These include bone morphogenetic proteins (BMPs), of which, BMP2, BMP4, BMP5, and BMP7 are highly expressed in the cardiac mesoderm and/or septum transversum mesenchyme (Lyons et al. 1989; Winnier et al. 1995; Zhang and Bradley 1996; Dudley et al. 1999; Solloway and Robertson 1999). However, detailed analyses of the specific sites of BMP expression in relation to the events of hepatogenesis have not been performed. The BMP receptors BMPRIA, BMPRII, and ActRIIA are clearly expressed in the endoderm (Mishina et al. 1995; Roelen et al. 1997). BMPs have been shown to foster a variety of epithelialmesenchymal interactions (Hogan 1999). For example, during tooth development, BMP4 from the epithelial ectoderm is necessary for Msx1 expression in the nearby mesenchyme (Vainio et al. 1993). Msx1 expression in the dental mesenchyme also requires FGF, establishing a precedent for a combination of the BMP and FGF signaling pathways effecting tissue development (Bei and Maas 1998).

Because of the difficulty in dissociating the septum transversum mesenchyme from the cardiac mesoderm or the endoderm, it is conceivable that some of this mesenchyme tissue was present in the early studies of cardiac induction of the liver, but not detected as a result of the lack of a distinct septum transversum marker (LeDouarin 1975; Gualdi et al. 1996; Jung et al. 1999b). Using newly discovered septum transversum mesenchyme markers, we were able to carefully monitor the presence of this tissue and find that it is included in typical explant cultures. Therefore, we investigated the possibility that the septum transversum mesenchyme contributes to the initial specification of the liver during endodermal patterning in conjunction with signals from the cardiac mesoderm. The results provide a new view of the classical paradigm of hepatic induction and illustrate how different mesodermal signals converge on a single domain of endoderm to promote tissue specification and subsequent morphogenesis.

\section{Results}

Septum transversum mesenchyme cells express Bmp4 at the time of hepatic specification

We used several different approaches to investigate a possible role for septum transversum mesenchyme cells in the initial phase of hepatic induction. First, we used a LacZ reporter gene inserted into the Bmp4 locus; this null allele faithfully reconstitutes the normal Bmp4 expression pattern (Winnier et al. 1995; Lawson et al. 1999). At E8.5, Bmp4 was shown previously to be expressed in the mesodermal regions of the foregut and hindgut (Jones et al. 1991). We found that at the 8 somite stage, the time of hepatogenesis, Bmp $4^{\text {LacZ }}$ is strongly expressed in the septum transversum mesenchyme as well as in the cardiac mesoderm (Fig. 1A, stm and cm). Notably, expression in the septum transversum mesen- chyme is particularly strong and is located immediately adjacent to the ventrolateral endoderm that becomes the liver. $B m p 4^{L a c Z}$ is not expressed in the prospective hepatic region of the ventral foregut endoderm itself (Fig. 1A, fe). At E9.5, BMP4 continues to be highly expressed in the septum transversum mesenchyme into which the liver bud is migrating (Fig. $1 \mathrm{~B}$, stm and see sections in Fig. 2B,C, below).

As a second approach to investigate whether the septum transversum cells are present during hepatic induction, we examined tissue explants of ventral foregut endoderm that were shown previously to induce a liver phenotype when exposed to either cardiac mesoderm or FGF (Gualdi et al. 1996; Jung et al. 1999b). In cocultures of ventral foregut endoderm with cardiogenic mesoderm isolated from the 2-6 somite stage, the cardiac cells progress to the beating stage within a day of culture and are readily distinguished (Gualdi et al. 1996).

Studies of Mrg1, a new septum transversum mesenchyme marker, recently revealed its expression in the mesenchyme cells closely apposed to the prospective hepatic endoderm (Dunwoodie et al. 1998). Our in situ hybridization revealed extensive Mrg1-positive cells permeating the endodermal portion of foregut endodermcardiac mesoderm cocultures (Fig. 1C, arrows pointing to purple patches); the sense strand control probe revealed no signal (Fig. 1D). Similarly, an antisense probe revealed Bmp4-positive cells intermingled with portions of the endoderm (Fig. 1E, arrows pointing to orange patches), as did $\beta$-galactosidase expression in a foregut endodermcardiac mesoderm explant from a Bmp $4^{\text {LacZ }}$ embryo (Fig. $1 \mathrm{~F}$, green-blue patches). Most significantly, endodermal explants isolated free of cardiogenic mesoderm, as judged by the absence of beating cardiac cells, exhibited a considerable number of $\beta$-galactosidase-positive cells from $B m p 4^{\text {LacZ }}$ embryos (Fig. 1G, green-blue patches). Therefore, we believe that in our endodermal explants from mouse embryos, and perhaps in earlier studies with the chick, septum transversum mesenchyme cells accompany the definitive endoderm cells and could play an inductive role for the liver. Such cells would be insufficient to induce hepatogenesis, however, because these foregut endoderm-septum transversum mesenchyme cultures neither express hepatic genes nor exhibit much outgrowth in the absence of cardiac mesoderm or FGF (Gualdi et al. 1996; Jung et al. 1999b).

\section{BMP4 null embryos exhibit a marked delay} in liver bud formation

The lack of BMP4 becomes lethal in homozygous mutant mice between 6.5 and 9.5 days of gestation, depending on the genetic background (Winnier et al. 1995; Dunn et al. 1997; Lawson et al. 1999). To study the role of BMP4 in early liver development, we used a Black Swiss $\times 129$ background, in which Bmp4 homozygous null embryos die at about 9.5 days of gestation (Lawson et al. 1999). Histological sections show that at the 12-13 and 17 somite stages (E9.0), as for wild-type embryos 
Rossi et al.

Figure 1. $B m p 4^{L a c Z}$ expression in the mouse embryo and explant cultures. $(A)$ At the time of hepatic specification, $\sim 8$ somite stage, Bmp $4^{\text {LacZ }}$ is expressed in the cardiac mesoderm $(\mathrm{cm})$ and more strongly in the septum transversum mesenchyme (stm), but is absent in the ventral foregut endoderm (fe). By $9.5 \mathrm{~d}$ of gestation, the liver bud has migrated away from the $\mathrm{cm}$, and into the stm, which continues to express $B m p 4^{\operatorname{LacZ}}(B)$. (C) In situ hybridization with an antisense probe to $\operatorname{Mrg} 1(D$, sense control). Mrg1 is expressed in explant cultures from $8.25 \mathrm{~d}$ mouse embryos, indicating that stm tissue is present in the cultures (beating cardiac cells in the culture are circled with a broken line). BMP4 is expressed in the cultures as well, both within the beating cardiac cells and the mesenchyme, as indicated by in situ hybridization $(E)$. The same $B m p 4$ expression pattern was observed within beating cardiac tissue and mesenchyme in $B m p 4^{\text {LacZ }}$ mouse explants $(F)$ and in the mesenchyme of cultures that do not contain beating cells $(G)$.
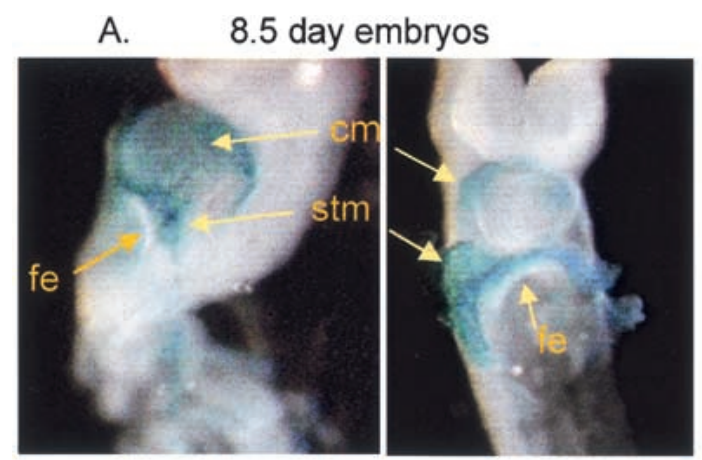

\section{B. 9.5 day embryo}

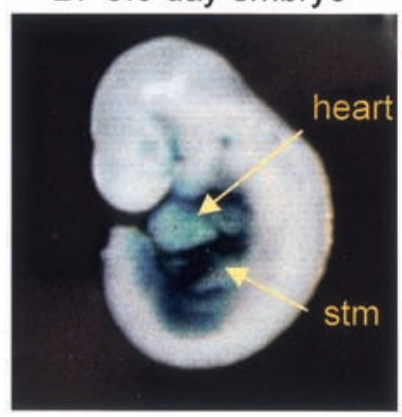

C. Mrg-1 Antisense
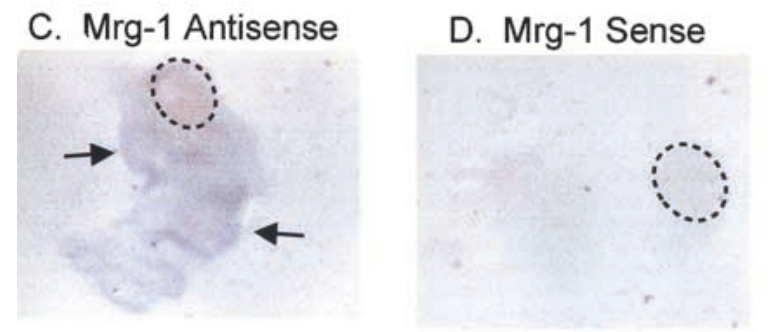

$\vdots^{\cdots}=$ beating
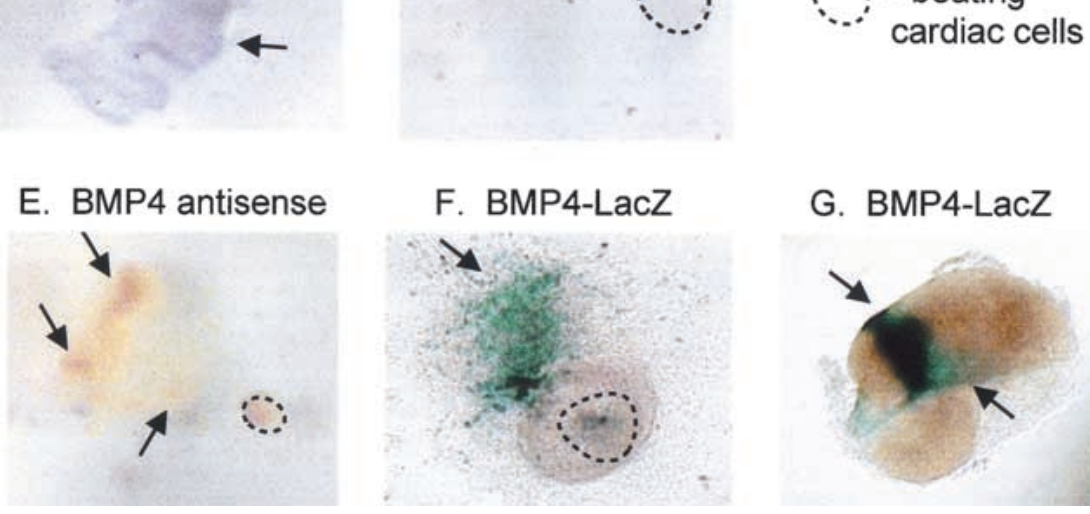

F. BMP4-LacZ

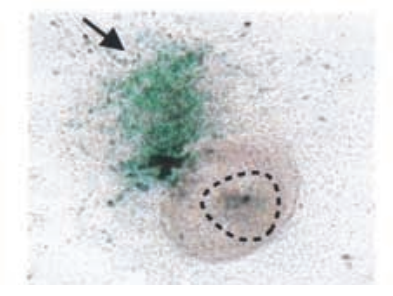

G. BMP4-LacZ

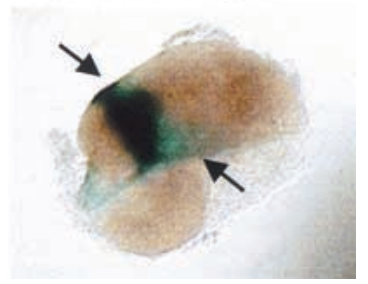

(Kaufman 1992), the foregut endoderm of $B m p 4^{L a c Z}$ heterozygous embryos begins to thicken adjacent to the mesenchyme of the septum transversum (Fig. 2A,B, arrowhead). The septum transversum mesenchyme cells clearly express BMP4 at this time, as demonstrated by $\beta$-galactosidase staining (Fig. $2 \mathrm{~B}$, arrow), whereas BMP4 is not expressed in the foregut endoderm itself at this stage (Fig. 2A,B; arrowheads). By the 22 somite stage, the hepatic endoderm has migrated into the BMP4-expressing septum transversum mesenchyme (Cascio and Zaret 1991) and some, but not all, of the latter tissue expresses BMP4 (Fig. 2C, arrow).

BMP4 homozygous null embryos at the 14-17 somite stages do not display the same thickening of the foregut endoderm observed in the Bmp4 heterozygotes. Rather, the foregut endoderm remains as a single layer of epithelium at this stage (Fig. 2D, arrowhead). Interestingly, morphological analysis of some $B m p 4$ mutants revealed ectopic expression of the $B m p 4^{L a c Z}$ gene in the foregut endoderm (Fig. 2D, blue-green staining cells at arrowhead). Others have also observed evidence for regulation of BMP gene expression by BMP signaling (Vainio et al. 1993).

By the 20 somite stage, some thickening of the foregut endoderm is evident in BMP4 homozygous null embryos (Fig. 2E, arrow). However, a distinct liver bud has not developed like that observed for heterozygous and wild- type embryos. Therefore, we detect a morphological delay in liver bud formation in the Bmp4 null embryos.

To explore the role of BMP4 in hepatogenesis further, early liver bud tissue was dissected from mid-teen somite stages of Bmp4 homozygous null and heterozygous embryos and subjected to RT-PCR analysis for albumin mRNA. The albumin gene is among the first liver-specific markers to be induced during normal mouse liver development (Gualdi et al. 1996). Albumin mRNA was present in tissues from embryos of all $B m p 4$ genotypes (Fig. 2F). Thus, the initial induction of hepatic gene expression takes place in the absence of BMP4 protein, despite the retardation of morphological outgrowth. In the limited number of embryos assayed, the levels of albumin mRNA, relative to the actin internal control, were lower in homozygous than in heterozygous embryos. This effect is probably due to there being fewer hepatic cells at the same stage in the null embryos (Fig. 2, cf. B and D).

\section{BMP signaling is required for endodermal induction of albumin gene expression}

As noted in the introductory section, multiple BMPs are expressed in the ventral foregut region. BMP2, in particular, is highly expressed at this time, in a pattern similar 

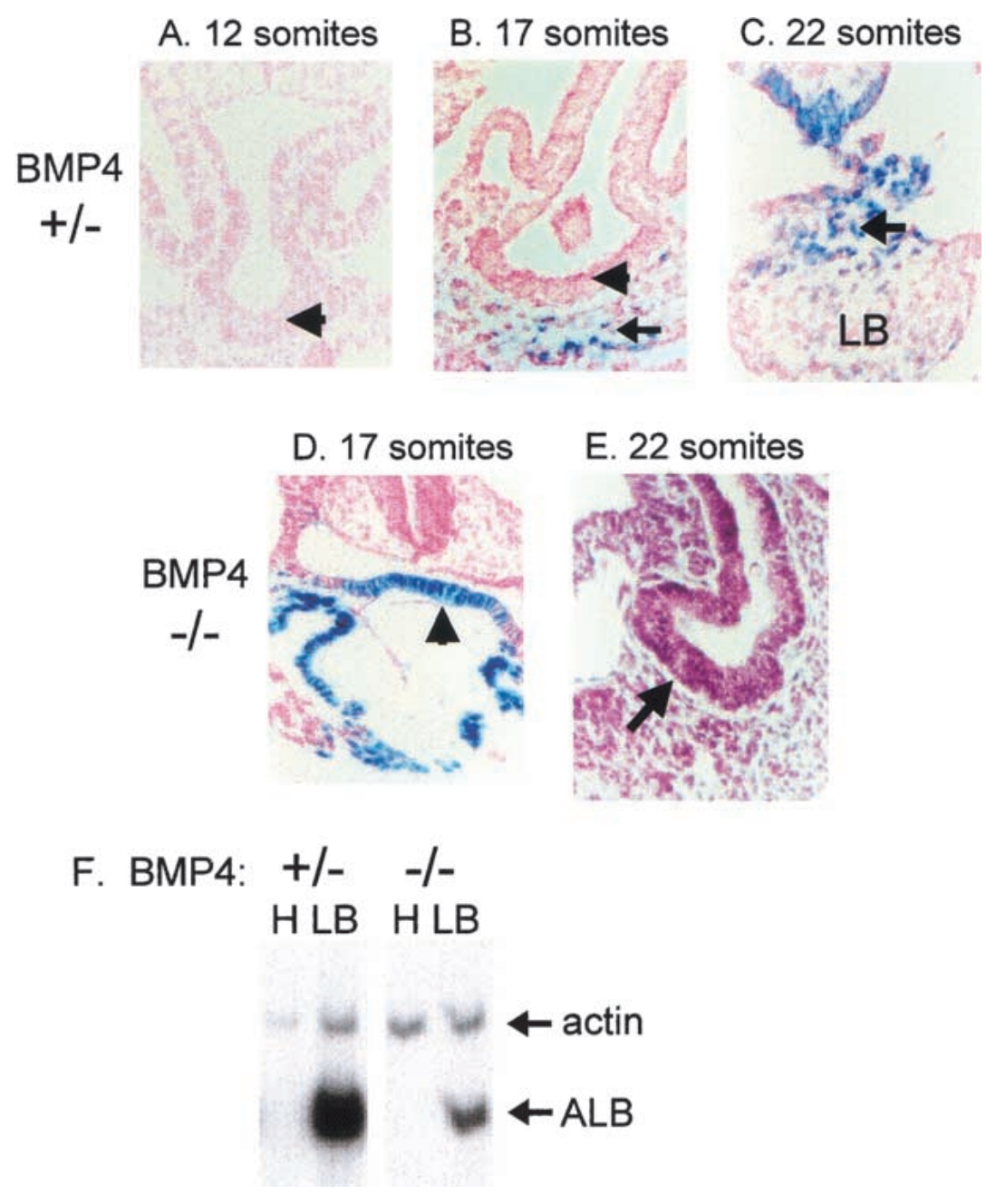

Figure 2. Delay in liver bud morphology in BMP4 homozygous null embryos. Transverse paraffin sections of $B m p 4^{\text {LacZ }}$ heterozygous embryos $(A-C)$ and homozygous null embryos $(D, E)$ showing the developing liver bud region. All sections at the same magnification. Twelve somite stage BMP4 heterozygous null embryos display a thickening of the hepatic endoderm ( $A$, arrowhead), and this tissue begins to move into the septum transversum mesenchyme (arrow) by the 17 somite stage $(B)$. At 22 somites, a liver bud (LB) is distinguishable embedded within the stm $(C)$. By contrast, 14-17 somite Bmp4 null embryos do not display the thickening of the foregut endoderm (arrowhead) evident in Bmp4 heterozygotes of comparable stage $(D)$, but the foregut endoderm (arrowhead) does begin to thicken by the 22 somite stage $(E)$. Therefore, there is a marked delay in formation of the liver bud of BMP4 homozygous null embryos. (F) RT-PCR analysis of hepatic regions (liver bud plus surrounding mesenchyme, lanes marked LB) from mid-teen somite stage embryos indicates the presence of albumin in both Bmp4 heterozygous and homozygous null embryos. Neural head tissue (lanes marked H), which does not express BMP4, isolated from the same embryos is used as a negative control. to BMP4 (Lyons et al. 1989; Furuta and Hogan 1998). Significantly, BMP2 and BMP4 share 92\% amino acid identity and common receptors and exhibit similar embryonic lethal homozygous null phenotypes (Zhang and Bradley 1996). To investigate the possibility of redundant BMP signaling, explants of ventral foregut endoderm, septum transversum mesenchyme, and cardiac mesoderm from 2-6 somite embryos were cultured in the presence of the Xenopus noggin protein (Xnoggin) (Smith and Harland 1992). This tissue explant system allows hepatic induction of the endoderm to occur in vitro (Gualdi et al. 1996). Noggin is an extracellular antagonist that binds to BMPs and prevents them from binding to their receptors (Zimmerman et al. 1996). Initial experiments were with ventral foregut explant cultures treated with purified Xnoggin; later experiments utilized a Chinese hamster ovary (CHO) cell supernatant collected from cells overexpressing Xnoggin or a control cell line (generously provided by R. Harland, UC Berkeley). After $48 \mathrm{~h}$ in culture, RNA was isolated from the explant colonies and assayed by RT-PCR for albumin gene induction. Because other early liver genes, such as $\alpha$-fetoprotein and transthyretin, are expressed at a low level in the undifferentiated gut endoderm, but albumin is not, we view albumin expression as a more discrete marker of hepatic induction (Gualdi et al. 1996; Jung et al. 1999b).

When eight explant colonies were cultured in $200 \mathrm{ng} /$ $\mathrm{mL}$ purified Xnoggin protein, six of them failed to induce albumin mRNA, relative to the actin internal control (see three samples in Fig. 3A, lanes 1-3), whereas two explants exhibited albumin expression nearly equal to actin levels (data not shown). By contrast, 9 of 10 untreated cultures exhibited levels of albumin expression equal to or greater than actin (Fig. 3A, lanes 4,5). Treatment of explant cultures with Xnoggin-containing supernatant also resulted in a dramatic inhibition of albumin gene induction; 17 of 27 explants failed to express albumin and 4 of 27 explants displayed markedly lower levels of albumin, relative to the actin internal control (low, Fig. 3B, left panel). By contrast, 19 of 23 explants cultured in the presence of control $\mathrm{CHO}$ cell supernatant expressed albumin levels equal to or greater than an actin internal control (medium and high levels, respectively, Fig. 3B). The control results were comparable with the range observed in the absence of $\mathrm{CHO}$ cell supernatant in the medium (Gualdi et al. 1996). The results indicate that BMP signaling is required for albumin gene 
Rossi et al.

A

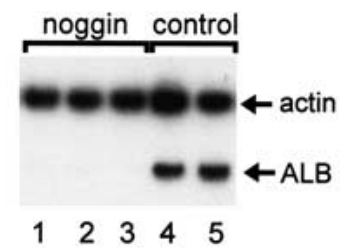

B $\mathrm{CHO}$ - noggin
supernatant (N)
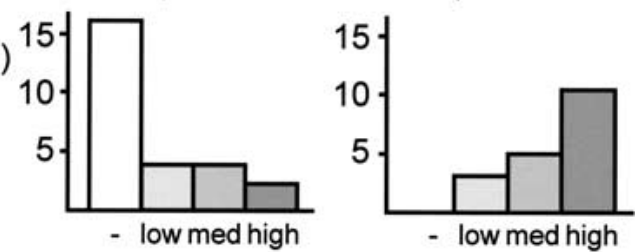

albumin mRNA relative to actin mRNA

C

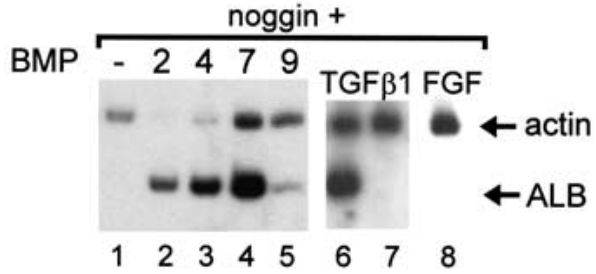

Figure 3. BMP signaling is required for hepatic specification in vitro. Foregut endoderm, cardiac mesoderm, and septum transversum mesenchyme tissue was dissected from 2-6 somite stage mouse embryos and cultured for $48 \mathrm{~h}$ in the presence of $\mathrm{CHO}$ cell supernatant containing noggin protein or control supernatant. (A) RT-PCR for albumin gene expression was performed on RNA isolated from the explants. Treatment with noggin (lanes 1-3) resulted in diminished albumin levels, compared with an actin internal control. By contrast, explants cultured in the presence of control CHO supernatant (lanes 4,5) expressed albumin in all cases, usually at levels higher than an actin internal control. $(B)$ The data represented graphically illustrate a summary of multiple experiments; $\mathrm{N}$, number of explants expressing no, low, medium, or high levels of albumin mRNA, relative to actin. Low, markedly lower levels of albumin than actin; medium, equal levels; high, higher levels of actin than albumin. (C) RT-PCR analysis of explants of foregut endoderm and cardiac mesoderm were cultured $48 \mathrm{~h}$ in $\mathrm{CHO}$ supernatant, noggin, or control, with the addition of exogenous factors.

expression in the explant assay. We speculate that the inability of noggin to inhibit albumin expression in all of the explants is likely due to the requirement of Xnoggin to penetrate through multiple layers of cells to antagonize BMPs, as will be addressed below.

To explore the specificity of BMP signaling, explants of foregut endoderm, septum transversum mesenchyme, and cardiac mesoderm tissue were cultured in the presence of $\mathrm{CHO}$ cell supernatant from Xnoggin-expressing cells or from the control CHO cell line, along with added BMP2, BMP4, BMP7, or BMP9. Five of six BMP2-treated colonies, six of eight BMP4-treated colonies, and two of two BMP7-treated colonies, all with BMPs at $200 \mathrm{ng} / \mathrm{mL}$, expressed levels of albumin equal to or greater than the actin control (Fig. 3C, lanes 1-4). Therefore, these BMPs, which are expressed in the ventral foregut region (Furuta et al. 1998), are individually able cause albumin induction in noggin-inhibited explants. BMP9, which is expressed after liver bud formation (Song et al. 1995), was able to rescue noggin inhibition of albumin in only three of six colonies (Fig. 3C, lane 5). One of two colonies treated with TGF- $\beta 1$ rescued albumin expression (Fig. $3 \mathrm{C}$, lanes 6,7). In limited experiments in which BMPs were added at a $50 \mathrm{ng} / \mathrm{mL}$ concentration to noggintreated explants, BMP2, but not BMP4, BMP9, or TGF- $\beta 2$ (data not shown) efficiently caused albumin induction. Together, these data support the hypothesis that redundancy in BMP signaling contributes to the delayed liver bud phenotype in the Bmp4 homozygous null mice, and suggest that BMP2, expressed in the ventral foregut region, can partially compensate for the absence of BMP4.

\section{$B M P$ activity is required for the initial induction of the albumin gene induction and the exclusion of expression of a pancreas gene}

Next, we asked whether exogenous FGF signaling could induce hepatic gene expression when BMP signaling is blocked. Explants containing ventral foregut endoderm, septum transversum mesenchyme, and cardiac mesoderm were treated with Xnoggin and $5 \mathrm{ng} / \mathrm{mL}$ FGF2, and cultured for $2 \mathrm{~d}$. RT-PCR analysis of RNA isolated from the explant cultures revealed that FGF2 was not able to efficiently restore albumin gene induction, as only two of eight explants exhibited albumin expression (Fig. 3C, lane 8). This low frequency is similar to the 4 of $27 \mathrm{nog}$ gin-treated cultures that were shown to express normal levels of albumin, probably reflecting the inefficiency of noggin accessibility to the mesenchyme. Therefore, neither cardiac mesoderm nor FGF2 are able to induce or maintain albumin gene expression in the absence of BMP signaling. These results show that the function of BMP is not solely to induce FGFs in the cardiac mesoderm.

We took two approaches to determine whether BMP is an inducing factor, essential for initial liver gene expression, or whether BMPs are responsible for maintaining albumin gene expression after hepatic specification. First, explants containing foregut endoderm, septum transversum mesenchyme, and cardiac mesoderm were isolated from 3-6 somite mouse embryos, prior to hepatic induction and cultured in vitro to determine the time required for albumin expression to be initiated. We found that 8 of 10 RNA samples isolated from colonies cultured between 10 and $13.5 \mathrm{~h}$ expressed albumin, whereas none of the explant colonies assayed after only $6.5 \mathrm{~h}$ expressed albumin (Fig. 4A). Therefore, induction of albumin gene expression requires $\sim 10-13 \mathrm{~h}$ in culture, compared with the $\sim 4-8 \mathrm{~h}$ it would take in vivo (Gualdi et al. 1996). According to models in which BMPs are required only for the maintenance of albumin expression, albumin induction might be initiated, then diminish in the presence of noggin. However, when explants were cultured in $\mathrm{CHO}$-noggin containing supernatant for 


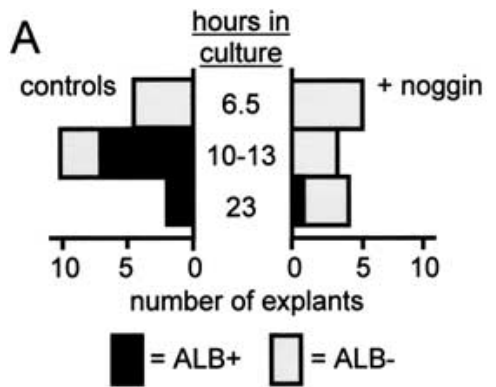

B $48 \mathrm{hr}$ cultures:
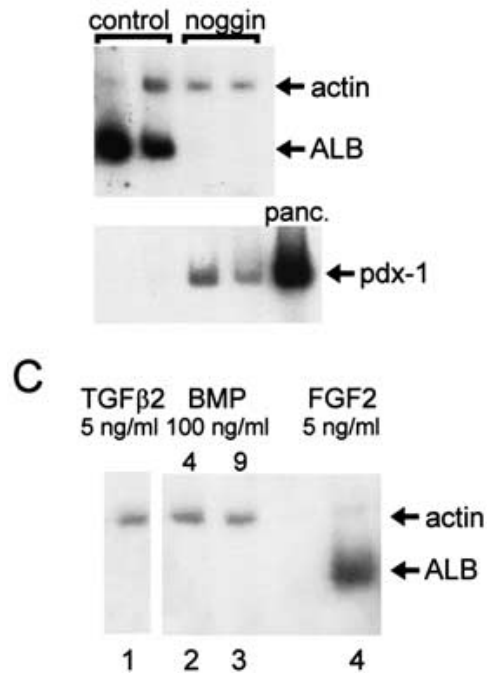

Figure 4. BMPs are necessary for primary hepatic induction. (A) Explants of foregut endoderm and cardiac mesoderm were isolated at the designated time points and assayed for albumin expression by RT-PCR. (B) RT-PCR data demonstrate the elevation of $p d x-1$ expression simultaneously with the suppression of albumin expression, in noggin-treated cultures, compared with the control. (C) RT-PCR data of endoderm cultured alone demonstrate that BMP and TGF 32 were not efficient inducers of albumin gene expression in cultures of ventral foregut endoderm in the absence of cardiac mesoderm, whereas FGF2 was efficient.

10-23 h, only one of seven colonies (isolated at $23 \mathrm{~h}$ ) was albumin positive by RT-PCR analysis. Apparently, when BMP signaling is inhibited, albumin expression is not initiated, indicating that BMPs play a role in the initial induction of the gene.

As a second approach to investigate how early BMP signaling is required for hepatogenesis, we evaluated the effect of noggin on pancreatic gene induction within the endoderm. Deutsch et al. (2001) showed recently that, when liver specification does not occur within the ventral foregut endoderm, pancreas gene activation is observed. If BMPs are required only for the maintenance of liver gene expression, then noggin treatment would not affect the initial decision of liver versus pancreas gene activation. To investigate these possibilities, we evaluated the expression of $p d x-1$, encoding an essential homeobox-containing transcription factor and among the first pancreatic genes to be activated (Jonsson et al. 1994; Guz et al. 1995; Offield et al. 1996). We find that in the presence of CHO-noggin, $p d x-1$ is activated, while albumin is not, whereas in the presence of control supernatant, albumin is expressed and $p d x-1$ is not $(n=4$, Fig. 4B). These data are consistent with BMP signaling playing a primary role in hepatic induction by helping FGF to exclude a pancreatic fate within the ventral endoderm.

Finally, we determined whether exogenous BMPs can induce albumin gene expression in cultures of foregut endoderm and septum transversum mesenchyme in the absence of cardiac mesoderm. Explants from 2-6 somitestage mouse embryos were cultured with BMP4, BMP9, TGF $\beta 2$, or FGF2. Of a total of seven colonies treated with different concentrations of BMP4, six failed to express albumin after $48 \mathrm{~h}$ in culture (Fig. $4 \mathrm{C}$, lane 2). Similarly, TGF $\beta 2$ and BMP9 were not efficient albumin inducers (Fig. 4C, lanes 1,3). By contrast, five of five colonies treated with FGF2 at $5 \mathrm{ng} / \mathrm{mL}$ were albumin positive (Fig. 4C, lane 4). Taken together, the above data show that cardiac mesoderm or FGF are needed in combination with BMP signaling from the septum transversum mesenchyme to induce hepatogenesis within the endoderm.

\section{BMP signaling positively regulates GATA4 gene expression in hepatic endoderm}

The albumin gene enhancer has essential binding sites for the transcription factors HNF3, GATA4, NF-1, and C/EBP (Herbst 1989; Liu et al. 1991; Bossard and Zaret 1998). One mechanism by which BMPs may control liver gene expression is via regulation of these factors. Recent studies have demonstrated that in some circumstances, BMPs are able to induce the expression of GATA factors (Maeno et al. 1996; Andree et al. 1998; Monzen et al. 1999). In vivo footprinting studies showed that a GATA site is occupied at the albumin transcriptional enhancer in undifferentiated endoderm, leading to the suggestion that this factor endows cells with the competence to activate liver genes in response to inductive signals (Bossard and Zaret 1998; Zaret 1999). To determine whether BMPs regulate GATA4 gene expression in nascent hepatic endoderm, in situ hybridizations were performed with GATA4 antisense and sense riboprobes.

Ventral foregut explants cultured with control $\mathrm{CHO}$ cell supernatant and hybridized to the gata 4 antisense riboprobe revealed the presence of GATA4 mRNA in both the cardiac mesoderm and surrounding tissue regions, including foregut endoderm (Fig. 5A, see arrows pointing to reddish patches). This pattern agrees with the expression of Gata4 in these tissues in intact embryos (Arceci et al. 1993; Laverriere et al. 1994). Interestingly, three of four explants cultured in the presence of noggin exhibited virtually no hybridization to the Gata4 antisense riboprobe (Fig. 5B), like the sense riboprobe controls (Fig. 5C). These data show that BMP signaling is critical to maintain the expression of a transcription factor that is essential for expression of albumin and other 


\section{A. $\mathrm{CHO}$-control supe.}

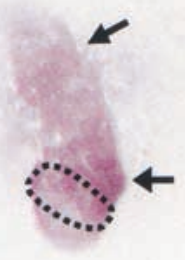

GATA-4 antisense probe

\section{C. $\mathrm{CHO}$-control supe.}

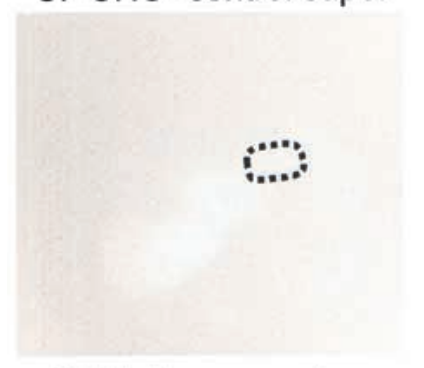

\section{:...: = beating cardiac cells}

\section{GATA-4 sense probe}

Figure 5. GATA4 expression dependent on BMP signaling. $(A)$ In situ hybridization with a GATA4 antisense probe detects significant GATA4 expression in explant colonies (arrows to purple patches). (B) When colonies are cultured in the presence of noggin, there is a drastic reduction of GATA4 expression, to the background level seen in the sense control $(C)$.

liver genes and, therefore, may play a role in hepatic developmental competence of the endoderm.

BMP4 plays a role in outgrowth and migration of nascent hepatic cells

As hepatic cells colonize the septum transversum mesenchyme, both move toward the midgut, caudal to the developing heart. In explants cultured for $48 \mathrm{~h}$, this is manifest in the proliferation and outgrowth of the foregut endoderm, away from the cardiac area of the culture (Jung et al. 1999b). When explant cultures from $B m p 4^{L a c Z}$ heterozygous embryos are fixed and stained after only $24 \mathrm{~h}$, the BMP4-expressing region of the cultures is near to, and predominantly overlapping with, the beating cardiac cells (Fig. 6A, see green-blue stained patches of $\beta$-galactosidase-positive cells and orangecircled cardiac cells). In these cultures, the endodermal portion has already begun to move away from the cardiac domain (Fig. 6A, black arrows). Interestingly, after 48 h, the BMP4-expressing region of the culture is now distant from the beating cardiac cells (Fig. 6B, green-blue patches, see arrows representing cell movement). This phenotype appears to recapitulate the movement of the septum transversum mesenchyme cells and hepatic endoderm away from the cardiac domain, as seen in vivo.

When wild-type explants of ventral foregut endoderm,

septum transversum mesenchyme, and cardiac mesoderm tissue were cultured in the presence of noggin, there was no inhibition of morphological outgrowth (Fig. 6C, note large blue-circled area). Note that it was not feasible to add more noggin, because control CHO supernatant began to generally inhibit growth if several-fold higher concentrations were used. Bmp4 null explants in the absence of noggin similarly exhibited normal growth
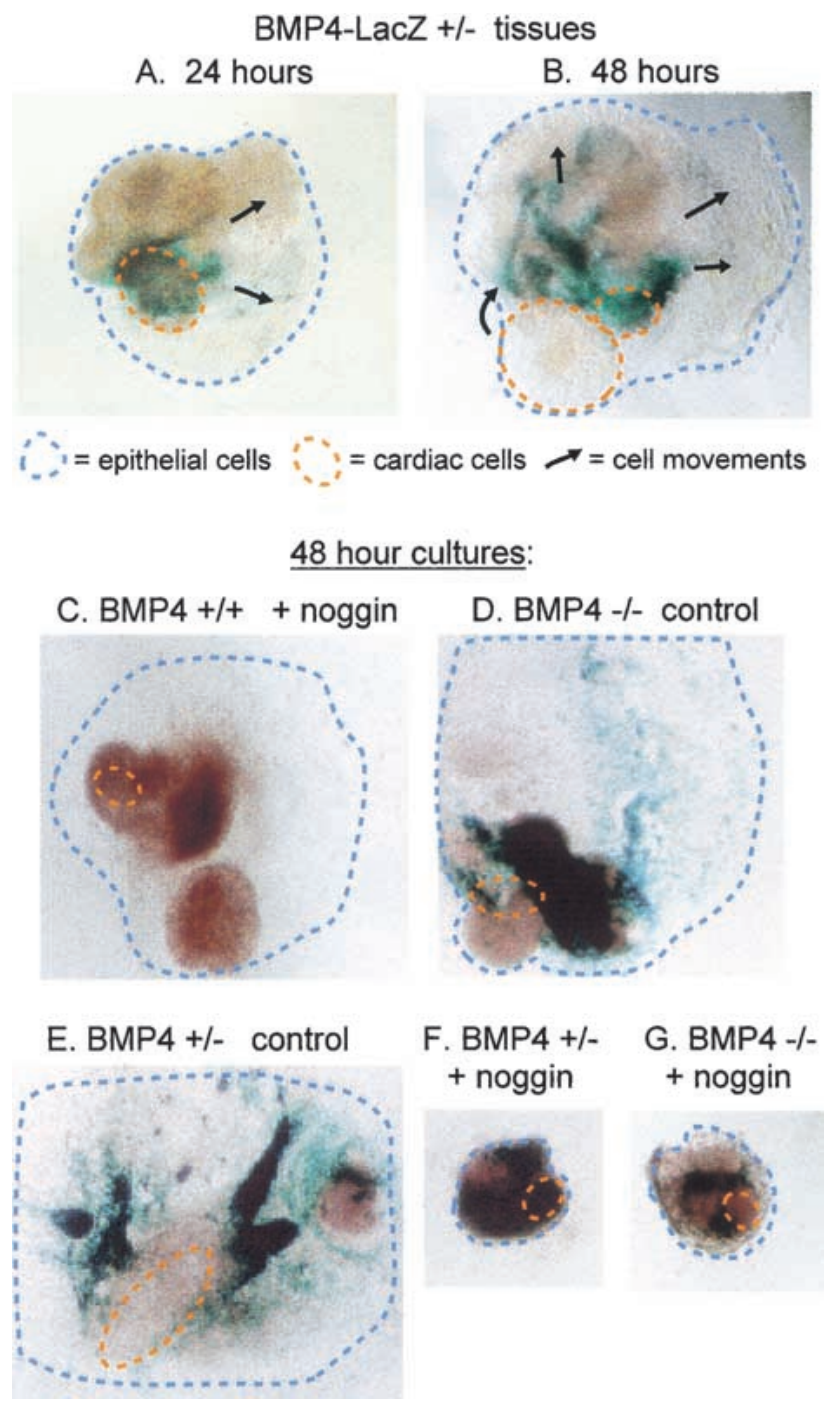

Figure 6. BMP signaling required for morphogenetic growth in vitro. $\beta$-Galactosidase staining for Bmp4 expression at $24 \mathrm{~h}(A)$ and $48 \mathrm{~h}(B)$, indicates that by $48 \mathrm{~h}$ the BMP4-expressing domains of the explant have moved away (arrows) from the beating cardiac cells (circled), similar to the movement of nascent hepatocytes and the septum transversum mesenchyme in embryos. The thickest tissue areas appear brown. $\beta$-Galactosidase staining of explant colonies indicates that wild-type $(C)$ explants treated with noggin and $B m p 4$ heterozygous explants treated with control supernatant $(F)$ exhibit a typical spreading morphology. Heterozygous Bmp4 explants cultured in noggin $(E)$, or Bmp4 null explants in noggin $(D)$ do not flatten and remain rounded, indicating a dependency on BMP signaling for morphogenetic growth. 
(Fig. 6D). However, if BMP signaling is redundant and if liver bud outgrowth is highly sensitive to low BMP concentrations (e.g., Fig. 2D,E), the amount of noggin protein we used might not penetrate between cells of the wild-type explant sufficiently to completely inhibit BMP signaling. To test this hypothesis, we evaluated the outgrowth of explants from heterozygous $B m p 4^{\text {LacZ }}$ embryos cultured in the presence of noggin. Note that heterozygous and homozygous $B m p 4^{L a c Z}$ explants cultured in the presence of control CHO supernatant exhibited the normal, flattened outgrowth of the endodermal epithelium, and the $\beta$-galactosidase-positive cells moved away from the cardiac area by $48 \mathrm{~h}$ in culture (Fig. 6C,E).

Strikingly, both $B m p 4^{L a c Z}$ heterozygous and $B m p 4$ null explants exhibited an aberrant morphology when cultured in the presence of Xnoggin (Fig. 6F,G). These colonies did not flatten or spread like the wild-type tissues; rather, they remained rounded and condensed throughout the culture period. In the presence of the BMP antagonist, wild-type explants apparently still receive a sufficient level of BMP to promote morphogenesis (Fig. 6C). The Bmp $4^{\text {LacZ }}$ heterozygous embryos express half the levels of BMP4, and the addition of Xnoggin apparently reduces BMP levels so low that a morphogenic response is not achieved (Fig. 6E). BMP signaling, therefore, is necessary for the morphological changes that follow the initial specification of hepatocytes.

\section{Discussion}

The role of the cardiac mesoderm in hepatic specification has been well documented and serves as a general paradigm for the induction of organ development (LeDouarin 1975; Houssaint 1980; Fukuda-Taira 1981; Gualdi et al. 1996; Jung et al. 1999b). Although chick embryo transplant studies established a critical role for septum transversum mesenchyme tissue in secondary phases of hepatic induction, the contribution of this tissue to the earliest induction step has not been investigated (LeDouarin 1975; Sherer 1975). In this study, we re-evaluated the original hypothesis that cardiac mesoderm was necessary and sufficient to induce the liver and demonstrated a role for the septum transversum mesenchyme in this process. The septum transversum mesenchyme is in close contact with the ventral foregut endoderm at the time of hepatic specification and is a source of BMPs. BMPs have been shown to act in a multitude of developmental processes, especially fostering interactions between tissue layers (Hogan 1996). Therefore, we conclude that liver induction from the endoderm, and pancreas exclusion (Deutsch et al. 2001), is the product of signaling from two distinct mesodermal sources, the cardiogenic mesoderm and the septum transversum mesenchyme.

To detect septum transversum cells in explants, we used two markers; Mrg1, which is specific for septum transversum mesenchyme (Dunwoodie et al. 1998) and $B m p 4$, which is expressed at particularly high levels in this tissue (Winnier et al 1995). By in situ hybridization, we found both markers present in explant domains that had previously been considered to be endoderm alone. $B m p$ expression persists in the septum transversum as the newly specified hepatocytes migrate into that mesenchyme, to form the liver bud (Winnier et al. 1995). Therefore, we investigated the contribution of BMP signaling to both the initial specification and the subsequent morphogenetic phase of liver development.

Although Bmp4 homozygous null embryos began to develop a liver bud, there was a significant delay in the formation of the liver primordium. $B m p 2$, which is very similar in sequence to $B m p 4$, is expressed in a similar pattern in the mesenchyme surrounding the foregut and in the cardiac mesoderm, and could potentially compensate for Bmp4 in homozygous null embryos (Lyons et al. 1989). Bmp2 homozygous null embryos die by E9 from cardiac defects and the absence of an amnion (Zhang and Bradley 1996). Because lethality in either null Bmp2 or null Bmp4 embryos occurs shortly after the time of hepatogenesis (Winnier et al. 1995; Zhang and Bradley 1996), the advantage of our explant assay is that we can isolate the tissues earlier and bypass secondary effects seen in later stage null embryos. Redundancy in BMP signaling during development has been shown to effect phenotypes in several different Bmp null mice (Dudley et al. 1999).

Although our noggin-antagonized explant experiments demonstrated that BMPs are necessary to induce albumin gene expression, we conclude that BMPs are not sufficient for such induction. This is because foregut endoderm and septum transversum mesenchyme, cultured with exogenous BMP but without cardiac mesoderm or FGF, does not efficiently progress to an albumin-expressing stage. In other experiments presented here and published previously, FGFs were shown to induce albumin gene expression in endoderm tissue cultured alone (Fig. 4C; Jung et al. 1999b). The present study now shows that these FGF-treated explants almost certainly contained mesenchymal cells that produced BMP. We had noted previously that such explants usually contained fibroblastic cells, but the function of these cells was unknown (Gualdi et al. 1996; Jung et al. 1999b; Deutsch et al. 2001). Further support of the requirement of BMPs was gained through the experiment in which ventral foregut endoderm explants treated with noggin were shown to be deficient in response to FGF2 (Fig. 3C).

Consistent with the notion that BMPs are involved in the primary induction of liver, we found that in noggintreated explants, the early pancreatic marker, $p d x-1$, was activated. This observation reflects the recent finding that when ventral foregut endoderm is not induced to become liver, it expresses pancreas genes as a default developmental program (Deutsch et al. 2001). However, BMP signaling must not be inhibitory to pancreas specification, per se, because in the absence of cardiac mesoderm or FGF, endoderm surrounded by BMP-positive mesenchyme initiates pancreas development. Thus, BMPs probably help endow the endoderm with the competence to respond to FGF signals, when the latter are induced in the cardiac mesoderm (Jung et al. 1999b). We 
Figure 7. Model for the roles of BMPs in hepatogenesis. Our data suggest that BMPs affect various phases of early of liver development. The septum transversum mesenchyme is in close contact with the presumptive hepatic endoderm, prior to hepatic induction by cardiac mesoderm (left). BMPs induce or maintain Gata4 expression in the foregut endoderm, which may impart hepatic competence. BMPs then act in combination with FGFs to promote liver gene expression and inhibit pancreas gene expression during endodermal patterning (center). Finally, BMPs expressed in the septum transversum mesenchyme are required for proper movement of the hepatoblasts into that tissue (right).

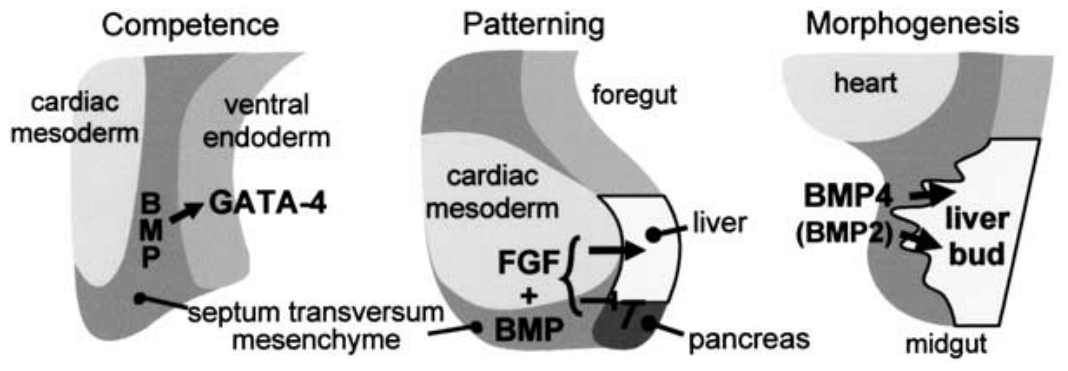

conclude that BMPs influence cell fate decisions in the early foregut and that the septum transversum mesenchyme plays an earlier role in hepatogenesis than previous studies suggested (LeDouarin 1975; Fukuda-Taira 1981).

The synergistic effect of a combination of BMP and FGF signaling has been described for many developmental processes, including limb, lung, bone, tooth, and somite development (Niswander and Martin 1993; Ono et al. 1996; Neubuser et al. 1997; Buckland et al. 1998; Merino et al. 1998; Jung et al. 1999a), and the data reported here suggest that these factors operate coordinately during liver development as well. Barron et al. (2000) recently expanded on their previous finding that, together, BMP2 and FGF4 are able to induce cardiac differentiation via regulation of the transcription factors $\mathrm{cNkx} 2.5$ and SRF, in nonprecardiac mesoderm from stage 6 avian embryos (Sugi and Lough 1995). They showed that ectopic cardiac induction occurs after addition of BMP2 or BMP4 only, and not other BMPs, activin A, insulin, or LIF. Similarly, cardiogenic differentiation is attained only with FGF2 and FGF4; and other factors including FGF7, activin A, and insulin could not substitute for these FGFs. Thus, both FGF2/FGF4 and BMP2/BMP4 were necessary for cNkx2.5 and SRF expression (Barron et al. 2000).

Previous work in our laboratory identified a region of the albumin gene transcriptional enhancer that confers liver-specific gene expression and contains a binding site for a GATA factor (Bossard and Zaret 1998). Furthermore, Gata4 homozygous null mice display defects in ventral foregut development (Kuo et al. 1997; Molkentin et al. 1997) and GATA4 is intrinsically required for endoderm development (Narita et al. 1997). BMPs have been shown to regulate expression of GATA factors in other systems, for example, normal vertebrate hematopoeisis requires GATA2 transcription factor activity, which is up-regulated in ventral mesoderm by BMP4 (Maeno et al. 1996). This study also showed that BMP4 from one germ layer regulates Gata2 expression in an adjacent germ layer, similar to our finding that BMPs in the mesenchyme control Gata4 expression in the neighboring endoderm.

$B m p 4^{\text {LacZ }}$ heterozygous null in vitro foregut explant cultures mimic the morphological movements occurring in the embryo, as the septum transversum mesenchyme begins to pull away from the cardiac mesoderm and toward the midgut, following hepatic specification. Heterozygous or homozygous null $B m p 4$ embryo explants cultured in the presence of noggin do not exhibit the typical flat, spreading morphology seen in the wild-type explants or heterozygous explants without noggin treatment. Rather, these tissues remain in a compact mass. These in vitro results reflect the delay in liver bud formation observed in the homozygous Bmp4 null embryos.

In conclusion, we propose that liver development is controlled coordinately by BMPs and FGFs from two distinct mesodermal sources, the septum transversum mesenchyme and cardiac mesoderm (Fig. 7). Expression of the essential transcription factor GATA4 in the foregut endoderm requires BMP signaling, suggesting that BMP acts in hepatogenesis via a pathway involving this transcription factor. Because BMPs are expressed in the septum transversum mesenchyme prior to hepatogenesis and because GATA4 is detected in presumptive hepatic endoderm, BMPs appear to impart hepatic competence to the endoderm. We suggest that BMPs contribute to endodermal patterning by allowing the endoderm to induce liver gene expression in response to FGFs, and consequently prevent induction of the pancreas lineage. Morphological defects are detected in noggin-antagonized explants from Bmp4 null embryos as well as in heterozygous Bmp4 embryos, demonstrating a role for BMPs in formation of the liver bud. This work extends the classical view of septum transversum mesenchyme in liver development to include roles in the endowment of hepatic competence and the initial specification of liver gene expression, in addition to liver bud morphogenesis. Further detailed analyses of mesodermal signaling sources will facilitate our understanding of how different tissues arise from multipotent gut endoderm.

\section{Materials and methods}

Embryo tissue isolation, tissue culture, and RNA analysis

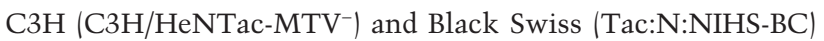
mice were obtained from Taconic (Germantown, NY). 
$B m p 4^{L a c Z}$ mice were generated as described (Dunn et al. 1997; Lawson et al. 1999). Noon of the day of the vaginal plug is $0.5 \mathrm{~d}$ post coitum. Embryo tissues were harvested at day 8-8.5 and staged according to Theiler (Theiler 1989). Embryo tissues were dissected in $1 \times$ PBS under a $60 \times$ dissecting microscope with electrolytically etched tungsten needles as described (Hogan et al. 1994; Gualdi et al. 1996). Explants were cultured in 8-well glass microwell slides (LabTek) coated with type I rat tail collagen (Collaborative Biomedical Products) in DMEM (BRL) containing $10 \%$ calf serum (Hyclone). Cultures were maintained at $37^{\circ} \mathrm{C}$ and $5 \% \mathrm{CO}_{2}$ air. RNA was isolated by cesium chloride gradient centrifugation and subjected to RT-PCR with actin and albumin primers as described (Gualdi et al. 1996; Jung et al. 1999b). Actin primers for PCR were added to the reactions after 6-8 cycles with albumin primers. Multiple PCR cycle steps were analyzed by gel electrophoresis, to be sure that the reactions were in the exponential range of PCR.

\section{BMP4 $4^{\text {Lacz }}$ genotype analysis}

Embryos were dissected free of extraembryonic membranes in $1 \times$ PBS and the neural portion removed into a buffer solution containing $50 \mathrm{mM} \mathrm{KCL}, 10 \mathrm{mM}$ Tris- $\mathrm{HCl}(\mathrm{pH} 8.3), 2.5 \mathrm{mM}$ $\mathrm{MgCl}_{2}, 0.1 \mathrm{mg} / \mathrm{mL}$ gelatin, $0.45 \%$ NP-40, $0.45 \%$ Tween 20 , for genotyping. A proteinase $\mathrm{K}$ digestion was carried out at $55^{\circ} \mathrm{C}$ for 3-18 h, followed by $10 \mathrm{~min}$ at $98^{\circ} \mathrm{C}$ for inactivation of the enzyme. Five microliters of the buffer solution and digested tissue was used in the PCR reaction with the following conditions: hot start was carried out at $94^{\circ} \mathrm{C}$ for $10 \mathrm{~min}$, then $75^{\circ} \mathrm{C}$ for $10 \mathrm{~min}$; Taq polymerase was added at this point, and reactions continued for 30-35 cycles at $94^{\circ} \mathrm{C}$ for $1 \mathrm{~min}, 61^{\circ} \mathrm{C}$ for $1 \mathrm{~min}$, and $72^{\circ} \mathrm{C}$ for $2 \mathrm{~min}$. The neo primer sequences used to detect the transgene were as described previously (Dunn et al. 1997), and the sequences of the primers used to detect the endogenous BMP4 gene were as follows: BMP4-1, 5'-ACCGAATGCTGAT GGTCGTT-3'; BMP4-2, 5'-CCTCATGTAATCCGGAATGA-3'.

\section{$B M P 4^{L a c Z}$ expression}

Embryos were fixed in $4 \%$ paraformaldehyde buffered at $\mathrm{pH} 7.4$ with $1 \times \mathrm{PBS}$ at $4^{\circ} \mathrm{C}$ for $30 \mathrm{~min}$ to $1 \mathrm{~h}$, washed with $1 \times \mathrm{PBS}$ on ice twice for $10 \mathrm{~min}$, then stained in X-gal solution: $0.2 \% \mathrm{X}$-gal, 2 $\mathrm{mM} \mathrm{MgCl}$, $5 \mathrm{mM}$ potassium ferricyanide, $5 \mathrm{mM}$ potassium ferrocyanide, $0.02 \%$ NP-40 prepared in $1 \times$ PBS, overnight at $37^{\circ} \mathrm{C}$. Then, embryos were rinsed twice with $1 \times$ PBS for $10 \mathrm{~min}$, post-fixed in $4 \%$ paraformaldehyde/1× PBS, photographed digitally, and subsequently prepared for paraffin sectioning by standard procedures. Then, the embryos were embedded and sectioned at $5 \mu \mathrm{m}$. Slides were dried, deparafinized, counterstained with eosin, and cover mounted with Permount (Sigma).

$\beta$-Galactosidase was visualized overnight in cocultured tissues on slides after 24 or $48 \mathrm{~h}$ in culture, similar to above for whole embryos, but following the post-fix step, cultures were rinsed and stored in $1 \times$ PBS pending digital photography.

\section{In situ hybridization}

In situ hybridization was performed on explants after $48 \mathrm{~h}$ of culture and all solutions were DEPC treated. Tissues were rinsed twice with $1 \times$ PBS, and fixed in $4 \%$ paraformaldehyde buffered to $\mathrm{pH} 7.4$ in $1 \times$ PBS for $20 \mathrm{~min}$ on ice. Explants were washed twice for $10 \mathrm{~min}$ with $1 \times \mathrm{PBS}$ and dehydrated through a PBT $(1 \times \mathrm{PBS}+0.1 \%$ Tween 20$)-\mathrm{MeOH}$ gradient, and stored in $\mathrm{MeOH}$ at $-20^{\circ} \mathrm{C}$. Tissues were rehydrated through a reciprocal gradient. Tissues were then washed with $10 \mu \mathrm{g} / \mathrm{mL}$ proteinase $\mathrm{K}$ in PBT for $3 \mathrm{~min}$ at room temperature, twice with $2 \mathrm{mg} / \mathrm{mL}$ glycine in PBT for 5 min at room temperature, followed by two successive washes in PBT at room temperature. The cultures were then refixed in $0.2 \%$ glutaraldehyde $/ 4 \%$ paraformaldehyde for $20 \mathrm{~min}$ at room temperature and rinsed three times in PBT, followed by a rinse with $50 \% \mathrm{PBT} / 50 \%$ hybridization buffer (50\% formamide, $1.3 \times$ SSC at $\mathrm{pH} 4.5,5 \mathrm{mM}$ EDTA, $50 \mu \mathrm{g} / \mathrm{mL}$ tRNA, $0.2 \%$ Tween $20,0.5 \%$ CHAPS, $100 \mu \mathrm{g} / \mathrm{mL}$ heparin in DEPC $\mathrm{H}_{2} \mathrm{O}$ ), two successive rinses in hybridization buffer, and a 5 -h wash in hybridization buffer at $70^{\circ} \mathrm{C}$. Hybridization was carried out with Mrg-1 antisense and sense probes (as described in Dunwoodie et al. 1998), Bmp4 antisense and sense probes (as described in Winnier et al. 1995), or Gata4 antisense and sense probes (as described in Bossard and Zaret 2000) at $50 \mathrm{ng} / \mathrm{mL}$ in hybridization buffer overnight.

\section{Xnoggin production}

$\mathrm{CHO} d h \mathrm{fr}^{-}$and $\mathrm{CHO}$ B3.A4 Xnoggin producing cell lines are described in Lamb et al. (1993), and were generously provided by R. Harland. CHO dhfr ${ }^{-}$cells were cultured in $\alpha$-MEM plus nucleosides (GIBCO) plus 10\% dialyzed fetal bovine serum (Hyclone). CHO B3.A4 cells were cultured in $\alpha$-MEM minus nucleosides (GIBCO) plus 5\% dialyzed fetal bovine serum, 1 $\mathrm{mM}$ sodium pyruvate (GIBCO), and $0.1 \mathrm{mM}$ nonessential amino acid solution (GIBCO), with $80 \mu \mathrm{M}$ methotrexate (Sigma) only during selection. $\mathrm{CHO}$ cells were maintained at $37^{\circ} \mathrm{C}, 5 \% \mathrm{CO}_{2}$. For noggin production, both cell lines were grown to $90 \%$ confluence in 100-mm plates, and the medium was replaced with $5 \%$ defined calf serum (Hyclone) in DMEM. After three days, the supernatant was aspirated, centrifuged to remove dead cells, filtered through a $22 \mu \mathrm{m}$ filter, and stored in aliquots at $-20^{\circ} \mathrm{C}$. Western blots confirmed the presence of Xnoggin protein in the supernatants using 1A4, a mouse monoclonal antibody (R.Harland), diluted $1: 250$ in 5\% milk (Carnation). HRP conjugated anti-mouse IgG (Jackson Labs) was used as the secondary antibody followed by ECL visualization (Amersham). CHO supernatants were used in explant cultures at concentrations of $1: 3$ to 1:4 with $10 \%$ DCS DMEM media.

FGF2 was purchased from Sigma, as described previously (Jung et al. 1999b). BMP proteins were generally provided by Genetics Institute, Cambridge, MA.

\section{Acknowledgments}

We thank Richard Harland for Xnoggin and Xnoggin producing cell lines, Genetics Institute for purified BMPs, Sally Dunwoodie and Rosa Beddington for Mrg-1 riboprobe constructs, and Joonil Jung for assistance in embryo culture experiments. J.M. Rossi was supported in part by NIH graduate training grant GM07601. The research was supported by NIH grant GM36477 to K.S.Z.

The publication costs of this article were defrayed in part by payment of page charges. This article must therefore be hereby marked "advertisement" in accordance with 18 USC section 1734 solely to indicate this fact.

\section{References}

Andree, B., Duprez, D., Vorbusch, B., Arnold, H.H., and Brand T. 1998. BMP-2 induces ectopic expression of cardiac lineage markers and interferes with somite formation in chicken embryos. Mech. Dev. 70: 119-131.

Arceci, R., King, A., Simon, M., Orkin, S., and Wilson, D. 1993. Mouse GATA-4: A retinoic acid-inducible GATA-binding transcription factor expressed in endodermally derived tis- 
sues and heart. Mol. Cell. Biol. 13: 2235-2246.

Barron, M., Gao, M., and Lough, J. 2000. Requirement for BMP and FGF signaling during cardiogenic induction in non-precardiac mesoderm is specific, transient, and cooperative. Dev. Dyn. 218: 383-393.

Bei, M. and Maas, R. 1998. FGFs and BMP4 induce both Msx1independent and Msx1-dependent signaling pathways in early tooth development. Development 125: 4325-4333.

Bossard, P. and Zaret, K.S. 1998. GATA transcription factors as potentiators of gut endoderm differentiation. Development 125: 4909-4917.

- 2000. Repressive and restrictive mesodermal interactions with gut endoderm: Possible relation to Meckel's diverticulum. Development 127: 4915-4923.

Buckland, R.A., Collinson, J.M., Graham, E., Davidson, D.R., and Hill, R.E. 1998. Antagonistic effects of FGF4 on BMP induction of apoptosis and chondrogenesis in the chick limb bud. Mech. Dev. 71: 143-150.

Cascio, S. and Zaret, K.S. 1991. Hepatocyte differentiation initiates during endodermal mesenchymal interactions prior to liver formation. Development 113: 217-225.

Deutsch, G., Jung, J., Zheng, M., Lora, J., and Zaret, K.S. 2001. A bipotential precursor population for pancreas and liver within the embryonic endoderm. Development 128: 871-881.

Dudley, A.T., Godin, R.E., and Robertson, E.J. 1999. Interaction between FGF and BMP signaling pathways regulates development of metanephric mesenchyme. Genes \& Dev. 13: $1601-1613$.

Dunn, N.R., Winnier, G.E., Hargett, L.K., Schrick, J.J., Fogo, A.B., and Hogan, B.L. 1997. Haploinsufficient phenotypes in Bmp4 heterozygous null mice and modification by mutations in Gli3 and Alx4. Dev. Biol. 188: 235-247.

Dunwoodie, S.L., Rodriguez, T.A., and Beddington, R.S. 1998. Msg1 and Mrg1, founding members of a gene family, show distinct patterns of gene expression during mouse embryogenesis. Mech. Dev. 72: 27-40.

Furuta, Y. and Hogan, B.L. 1998. BMP4 is essential for lens induction in the mouse embryo. Genes \& Dev. 12: 3764 3775.

Fukuda-Taira, S. 1981. Hepatic induction in the avian embryo: Specificity of reactive endoderm and inductive mesoderm. J. Embryol. Exp. Morphol. 63: 111-125.

Gualdi, R., Bossard, P., Zheng, M., Hamada, Y., Coleman, J.R., and Zaret K.S. 1996. Hepatic specification of the gut endoderm in vitro: Cell signaling and transcriptional control. Genes \& Dev 10: 1670-1682.

Guz, Y., Montminy, M.R., Stein, R., Leonard, J. Gamer, L.W., Wright, C.V., and Teitelman, G. 1995. Expression of murine STF-1, a putative insulin gene transcription factor, in beta cells of pancreas, duodenal epithelium and pancreatic exocrine and endocrine progenitors during ontogeny. Development 121: 11-18.

Herbst, R.S., Friedman, N., Darnell, Jr., J.E., Babiss, L.E. 1989. Positive and negative regulatory elements in the mouse albumin enhancer. Proc. Natl. Acad. Sci. 86: 1553-1557.

Hogan, B.L. 1999. Morphogenesis. Cell 96: 225-233.

Houssaint, E. 1980. Differentiation of the mouse hepatic primordium. I. An analysis of tissue interactions in hepatocyte differentiation. Cell Differ. 9: 269-279.

Immerglück, K., Lawrence, P.A., and Bienz, M. 1990. Induction across germ layers in Drosophila mediated by a genetic cascade. Cell 62: 261-268.

Jones, C.M., Lyons, K.M., and Hogan, B.L. 1991. Involvement of bone morphogenetic protein-4 (BMP-4) and Vgr-1 in morphogenesis and neurogenesis in the mouse. Development 111: 531-542.
Jonsson, J., Carlsson, L., Edlund, T., and Edlund, H. 1994. Insulin-promoter-factor 1 is required for pancreas development in mice. Nature 371: 606-609.

Jung, H.S., Oropeza, V., and Thesleff, I. 1999a. Shh, Bmp-2, Bmp-4 and Fgf- 8 are associated with initiation and patterning of mouse tongue papillae. Mech. Dev. 81: 179-182.

Jung, J., Zheng, M., Goldfarb, M., and Zaret, K.S. 1999b. Initiation of mammalian liver development from endoderm by fibroblast growth factors. Science 284: 1998-2003.

Kaufman, M.H. 1992. The atlas of mouse development. Academic Press, San Diego.

Kuo, C.T., Morrisey, E.E., Anandappa, R., Sigrist, K., Lu, M.M., Parmacek, M.S., Soudais, C., and Leiden, J.M. 1997. GATA4 transcription factor is required for ventral morphogenesis and heart tube formation. Genes \& Dev. 11: 1048-1060.

Lamb, T.M., Knecht, A.K., Smith, W.C., Stachel, S.E., Economides, A.N., Stahl, N., Yancopolous, G.D., and Harland, R.M. 1993. Neural induction by the secreted polypeptide noggin. Science 262: 713-718.

Laverriere, A.C., MacNeill, C., Mueller, C., Poelmann, R.E., Burch, J.B., and Evans, T. 1994. GATA-4/5/6, a subfamily of three transcription factors transcribed in developing heart and gut. J. Biol. Chem. 269: 23177-23184.

Lawson, K.A., Dunn, N.R., Roelen, B.A., Zeinstra, L.M., Davis, A.M., Wright, C.V., Korving, J.P., and Hogan, B.L. 1999. $B m p 4$ is required for the generation of primordial germ cells in the mouse embryo. Genes \& Dev. 13: 424-436.

LeDouarin, N.M. 1975. An experimental analysis of liver development. Med. Biol. 53: 427-455.

Liu, J.K., DiPersio, C.M., and Zaret, K.S. 1991. Extracellular signals that regulate liver transcription factors during hepatic differentiation in vitro. Mol. Cell. Biol. 11: 773-784.

Lyons, K.M., Pelton, R.W., and Hogan, B.L. 1989. Patterns of expression of murine Vgrl and BMP-2a RNA suggest that transforming growth factor-beta-like genes coordinately regulate aspects of embryonic development. Genes \& Dev. 3: $1657-1668$.

Maeno, M., Mead, P.E., Kelley, C., Xu, R.H., Kung, H.F., Suzuki, A., Ueno, N., and Zon, L.I. 1996. The role of BMP-4 and GATA-2 in the induction and differentiation of hematopoietic mesoderm in Xenopus laevis. Blood 88: 1965-1972.

Merino, R., Ganan, Y., Macias, D., Economides, A.N., Sampath, K.T., and Hurle, J.M. 1998. Morphogenesis of digits in the avian limb is controlled by FGFs, TGF $\beta$ s, and noggin through BMP signaling. Dev. Biol. 200: 35-45.

Mishina, Y., Suzuki, A., Ueno, N., and Behringer, R.R. 1995. Bmpr encodes a type I bone morphogenetic protein receptor that is essential for gastrulation during mouse embryogenesis. Genes \& Dev. 9: 3027-3037.

Molkentin, J.D., Lin, Q., Duncan, S.A., and Olson, E.N. 1997. Requirement of the transcription factor GATA4 for heart tube formation and ventral morphogenesis. Genes \& Dev. 11: 1061-1072.

Monzen, K., Shiojima, I., Hiroi, Y., Kudoh, S., Oka, T., Takimoto, E., Hayashi, D., Hosoda, T., Habara-Ohkubo, A., Nakaoka, T., et al. 1999. Bone morphogenetic proteins induce cardiomyocyte differentiation through the mitogen activated protein kinase kinase kinase TAK1 and cardiac transcription factors Csx/Nkx 2.5 and GATA-4. Mol. Cell. Biol. 19: 7096-7105.

Narita, N., Bielinska, M., and Wilson, D.B. 1997. Wild-type endoderm abrogates the ventral developmental defects associated with GATA-4 deficiency in the mouse. Dev. Biol. 189: 270-274.

Neubuser, A., Peters, H., Balling, R., and Martin, G.R. 1997. Antagonistic interactions between FGF and BMP signaling 
pathways: A mechanism for positioning the sites of tooth formation. Cell 90: 247-255.

Niswander, L. and Martin, G.R. 1993. FGF-4 and BMP-2 have opposite effects on limb growth. Nature 361: 68-71.

Offield, M.F., Jetton, T.L., Labosky, P.A., Ray, M., Stein, R.W., Magnuson, M.A., Hogan, B.L., and Wright, C.V. 1996. PDX-1 is required for pancreatic outgrowth and differentiation of the rostral duodenum. Development 122: 983-995.

Ono, I., Tateshita, T., Takita, H., and Kuboki, Y. 1996. Promotion of the osteogenetic activity of recombinant human bone morphogenetic protein by basic fibroblast growth factor. $J$. Craniofac. Surg. 7: 418-425.

Panganiban, G.E., Reuter, R., Scott, M.P., and Hoffmann, F.M. 1990. A Drosophila growth factor homolog, decapentaplegic, regulates homeotic gene expression within and across germ layers during midgut morphogenesis. Development 110: 1041-1050.

Roelen, B.A., Goumans, M.J., van Rooijen, M.A., and Mummery, C.L. 1997. Differential expression of BMP receptors in early mouse development. Int. J. Dev. Biol. 41: 541-549.

Sherer, G.K. 1975. Tissue interaction in chick liver development: A reevaluation. II. Parenchymal differentiation: Mesenchymal influence and morphogenetic independence. DeV. Biol. 46: 296-308.

Smith, W.C. and Harland, R.M. 1992. Expression cloning of noggin, a new dorsalizing factor localized to the Spemann organizer in Xenopus embryos. Cell 70: 829-840.

Solloway, M.J. and Robertson, E.J. 1999. Early embryonic lethality in $B m p 5 ; B m p 7$ double mutant mice suggests functional redundancy within the 60A subgroup. Development 126: $1753-1768$

Song, J.J., Celeste, A.J., Kong, F.M., Jirtle, R.L., Rosen, V., and Theis, R.S. 1995. Bone morphogenetic protein-9 binds to liver cells and stimulates proliferation. Endocrinology 136: 4293-4297.

Sugi, Y. and Lough, J. 1995. Activin-A and FGF-2 mimic the inductive effects of anterior endoderm on terminal cardiac myogenesis in vitro. Dev. Biol. 168: 567-574.

Szuts, D., Eresh, S., and Bienz, M. 1998. Functional intertwining of Dpp and EGFR signaling during Drosophila endoderm induction. Genes \& Dev. 12: 2022-2035.

Theiler, K. 1989. The house mouse: Atlas of embryonic development. Springer-Verlag, New York.

Vainio, S., Karavanova, I., Jowett, A., and Thesleff, I. 1993. Identification of BMP-4 as a signal mediating secondary induction between epithelial and mesenchymal tissues during early tooth development. Cell 75: 45-58.

Wells, J.M. and Melton, D.A. 1999. Vertebrate endoderm development. Annu. Rev. Cell. Dev. Biol. 15: 393-410.

Winnier, G., Blessing, M., Labosky, P.A., and Hogan, B.L. 1995. Bone morphogenetic protein- 4 is required for mesoderm formation and patterning in the mouse. Genes \& Dev. 9: 21052116.

Zaret, K.S. 1999. Developmental competence of the gut endoderm: Genetic potentiation by GATA and HNF3/Forkhead proteins. Dev. Biol. 209: 1-10.

. 2000. Liver specification and early morphogenesis. Mech. Dev. 92: 83-88.

Zhang, H. and Bradley, A. 1996. Mice deficient for BMP2 are nonviable and have defects in amnion/chorion and cardiac development. Development 122: 2977-2986.

Zimmerman, L.B., De Jesus-Escobar, J.M., and Harland, R.M. 1996. The Spemann organizer signal noggin binds and inactivates bone morphogenetic protein 4. Cell 86: 599-606. 


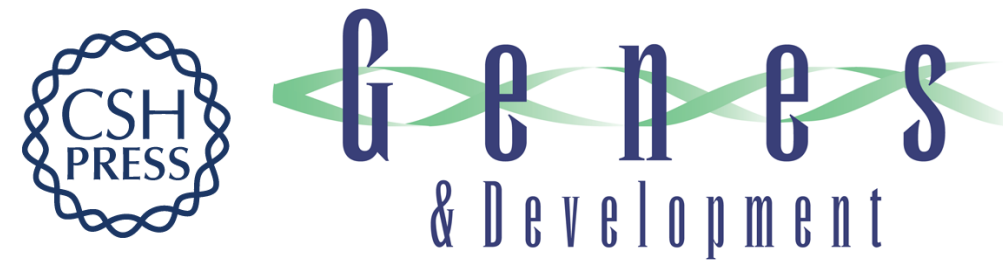

\section{Distinct mesodermal signals, including BMPs from the septum transversum mesenchyme, are required in combination for hepatogenesis from the endoderm}

Jennifer M. Rossi, N. Ray Dunn, Brigid L.M. Hogan, et al.

Genes Dev. 2001, 15:

Access the most recent version at doi:10.1101/gad.904601

$\begin{array}{ll}\text { References } & \begin{array}{l}\text { This article cites } 56 \text { articles, } 29 \text { of which can be accessed free at: } \\ \text { http://genesdev.cshlp.org/content/15/15/1998.full.html\#ref-list-1 }\end{array}\end{array}$

License

Email Alerting Receive free email alerts when new articles cite this article - sign up in the box at the top Service right corner of the article or click here.

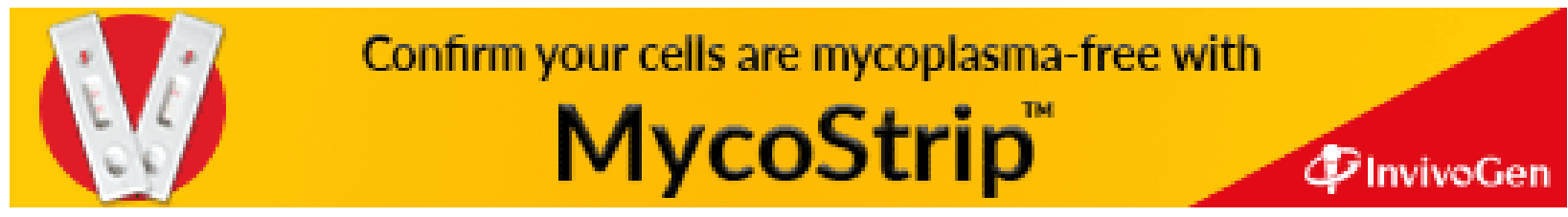

